\title{
Specificity of Incomplete Resistance to Mycosphaerella graminicola in Wheat
}

\author{
J. E. Krenz, K. E. Sackett, and C. C. Mundt
}

Department of Botany and Plant Pathology, 2082 Cordley Hall, Oregon State University, Corvallis 97331-2902.

Accepted for publication 31 December 2007.

\begin{abstract}
Krenz, J. E., Sackett, K. E., and Mundt, C. C. 2008. Specificity of incomplete resistance to Mycosphaerella graminicola in wheat. Phytopathology 98:555-561.

We examined interactions between wheat (Triticum aestivum) and Mycosphaerella graminicola, causal agent of Septoria tritici blotch, to determine whether specific interactions occur between host and pathogen genotypes that could be involved in eroding resistance. The moderate resistance of the wheat cultivar Madsen has eroded significantly in the Willamette Valley of Oregon since its release in 1990. Foote is a replacement cultivar expressing moderate resistance and was released in 2000. Isolates of M. graminicola were collected from Foote and Madsen in 2004 and 2005 and tested on each cultivar in growth chamber and green-

vidually and also when they were tested as bulks of isolates collected from the same cultivar. Though the resistance of Foote is still very effective in the field, isolates sampled from that cultivar at the end of the season in both 2004 and 2005 were of high virulence on Foote, while those collected from Madsen usually were of low virulence on Foote. Foote demonstrated qualitative reactions more typical of a major resistance gene that provides incomplete resistance. Madsen showed a more continuous variation in reaction to $M$. graminicola isolates. The mean of the isolates collected from Madsen caused significantly $(P \leq 0.05)$ more disease on Madsen than on Foote for the individual isolates collected in 2005, but not for those collected in 2004. Bulk populations collected from Madsen did not cause significantly more disease on Madsen than did isolates collected from Foote in either 2004 or 2005.
\end{abstract} house experiments. There was a significant $(P \leq 0.002)$ cultivar by isolate source interaction in all experiments when the isolates were tested indi-
Additional keywords: durable resistance, pathogen adaptation, selection.
The wheat (Triticum aestivum)-Mycosphaerella graminicola pathosystem, which results in the foliar disease Septoria tritici blotch, is extensively researched with well documented quantitative interactions, making it a very useful candidate for exploring the impact of incomplete resistance on pathogen population biology $(3,8,11,19,28)$. Both quantitative and qualitative resistance reactions to $M$. graminicola isolates have been observed in the same wheat genotype (11). Over 12 major genes conferring high levels of host resistance have been identified, and most have been mapped to specific regions of the wheat genome $(1,2,5,6$, $9,12,24)$. M. graminicola is an ascomycete fungus with a heterothallic, bipolar mating system that undergoes more than one sexual cycle per season (14). Sexual reproduction is followed by cycles of asexual reproduction by splash-dispersed pycnidiospores (conidia), which allow for the amplification of more fit genotypes and possible selection for traits such as increased virulence and aggressiveness (14). Gene-for-gene interactions have been demonstrated between wheat and $M$. graminicola $(7,20)$.

The Willamette Valley of Oregon is an ideal location to study this pathosystem because favorable environmental conditions allow for the development of Septoria tritici blotch epidemics, large off-season pathogen populations prevent genetic bottlenecks, geographic isolation prevents immigration of outside populations, and extensive sexual recombination occurs (27). In addition, ascospores are wind-dispersed throughout the Willamette Valley at the beginning of the season, suggesting that gene flow among fields is an important evolutionary force shaping the population structure of M. graminicola (C. C. Mundt, unpub-

Corresponding author: C. C. Mundt; E-mail address: mundtc@science.oregonstate.edu

doi:10.1094/PHYTO-98-5-0555

(c) 2008 The American Phytopathological Society lished data). All of these conditions increase the probability of detecting changes of variation in $M$. graminicola populations in response to the deployment of host resistance genes.

Opposing experimental results have occurred in the Willamette Valley regarding adaptation of $M$. graminicola populations to incomplete resistance. Cowger and Mundt (15) found little evidence of pathogen adaptation to host cultivar. In another study, isolates from Oregon cultivars Madsen and Stephens tested on both cultivars indicated evidence of adaptation but with no distinct preference for their cultivar of origin (29). Other research has found that isolates are better adapted to the host cultivar from which they originate than to other wheat cultivars $(3,4)$.

Host plant resistance to Septoria tritici blotch has been unstable in the Willamette Valley, which has resulted in significant changes in the cultivars grown. The cultivar Gene contains at least one major resistance gene, Stb6 (10), and possibly another, Stb4 (13). Gene was released in 1993 and previously undetected pathogen genotypes caused high disease levels after just 2 years of significant commercial production of Gene in the Willamette Valley (13). Moderate resistance of the cultivar Madsen has eroded in the field as well, though at a slower rate than that of Gene (26). The wheat cultivar Foote became popular in the Willamette Valley after its release in 2000, mainly because of its moderate resistance to $M$. graminicola.

The objective of this study was to explore specific interactions potentially involved in the erosion of incomplete resistance in the field using isolates of $M$. graminicola and the wheat cultivars Foote and Madsen. It is difficult to detect frequency changes in $M$. graminicola genotypes because high rates of recombination disperse pathogenicity alleles to many isolates, and it appears that commonly used neutral molecular markers are not linked to those under selection (25). Thus, the most reliable way to track the evolution of pathogen populations is through inoculations and phenotypic disease assessments. In our study, significant host 
cultivar $\times$ isolate source interactions were used as indicators of specificity. Furthermore, isolates of $M$. graminicola causing more disease on their cultivar of origin would be suggestive of adaptation to host of origin. The robustness of results was tested using different methodologies: both individual isolates and bulk populations were tested, and trials were carried out in both growth chamber and greenhouse environments.

\section{MATERIALS AND METHODS}

Host cultivars. Two commercially important cultivars that have been grown in the Willamette Valley of Oregon were chosen for this study. The cultivar Madsen was released in 1990, and upon release exhibited moderate resistance to $M$. graminicola. Growers and researchers have reported that this resistance has eroded substantially over time (26). The cultivar Foote was released in 2000 and demonstrated moderate resistance that is still observed in the field. Disease levels on Foote are generally between 25 and $40 \%$ of that on Madsen (C. C. Mundt, unpublished data).

Pathogen collection. Flag leaves of Foote and Madsen with visible lesions and pycnidia of $M$. graminicola were collected in late June 2004 and 2005. By this time of the season, multiple rain events had splash-dispersed conidia to upper canopy levels, maximizing the number of generations and, as a result, selection among isolates. Ascospores are widely distributed throughout the Willamette Valley in late fall/early winter (smaller ascospore showers also may occur in the spring [13]) and therefore each field was considered to be representative of the genetic diversity within the Willamette Valley (4). In 2004, leaves were collected at the Hyslop Crop Science Field Research Laboratory in Corvallis, OR. Leaves were randomly chosen from a single plot of each cultivar. In 2005, leaves were collected at Oregon State University's Botany and Plant Pathology Field Laboratory in Corvallis, OR. Due to an epidemic of stripe rust (caused by Puccinia striiformis f. sp. tritici) that affected Foote, flag leaves from both cultivars were collected in plots that had received a single fungicide application of Stratego (Bayer CropScience, Research Triangle Park, NC), a mixture of azoxystrobin and propiconazole, at a rate of 0.725 liter/ha 42 days prior to collection. This fungicide application controlled stripe rust to a degree that allowed $M$. graminicola to establish and increase. Resistance to neither triazole nor strobilurin fungicides has yet been reported in Oregon populations of $M$. graminicola. Twenty flag leaves were randomly chosen from each of four plots of the same cultivar and bagged separately. In both years, leaves were dried by leaving them uncovered and spread out on a lab bench for approximately 5 days. They were then grouped in bags according to cultivar and plot and placed in cold storage until processed.

Pathogen isolation. In 2004, all collected leaves were used to obtain isolates while, in 2005, five randomly chosen leaves from each plot were used. These leaves were cut into sections approximately 5 to $7 \mathrm{~cm}$ in length, clipped to glass microscope slides, placed in moist chambers constructed from glass petri dishes with wet filter paper, and left overnight. These conditions promoted the oozing of pycnidia in the leaf sections. The next day leaves were examined under a dissecting scope in a laminar flow hood. Cirrhi in separate lesions that were also not in contact with neighboring cirrhi were plucked off with a dental pick or tweezers and placed on yeast malt agar plates amended with gentamicin at $10 \mathrm{mg} / \mathrm{liter}$. Isolates from a single leaf section were put on the same plate. These isolates were allowed to grow for 3 to 5 days. Isolates that were not contaminated were then transferred to new plates, each plate being used for a single isolate. Approximately 1 month later isolates were transferred to yeast malt agar slants amended with gentamicin at $10 \mathrm{mg} / \mathrm{liter}$, sealed with parafilm for long-term storage, and refrigerated.

Isolate selection and experimental design. Six experiments were conducted (Table 1). Isolates used for the experiments were randomly chosen from those that were successfully grown on artificial media, with each isolate originating from a different leaf to avoid sampling the same genotype. The first experiment in the greenhouse (Table 1, experiment 6) used bulk populations of 14 isolates collected from both Foote and Madsen. The number of isolates used in these bulk populations was limited due to difficulties in obtaining isolates from the cultivar Foote. Because this trial indicated adaptation to Foote, we then evaluated individual isolates in growth chamber studies (insufficient temperature control precludes greenhouse studies from April to October). Initially, seven isolates from each 2004 bulk population were randomly chosen to evaluate the individual isolates separately, hereafter called the preliminary trial. Space constraints led to some contamination among pots in the growth chamber, and the data were not analyzed. However, isolate rankings from this preliminary trial were used to design a subsequent experiment (experiment 1), in which the number of isolates from each cultivar was reduced from seven to four.

The 2004 isolates that caused the most disease, the least amount of disease, and two intermediate levels of disease on the cultivar of origin in the preliminary trial were chosen for evaluation in the growth chamber as individual isolates (experiment 1) and as bulk populations (experiment 4). An identical sampling procedure was used to choose four isolates per cultivar from the 2005 collection (experiments 2, 3, and 5). The eight isolates from each year were tested individually on each cultivar in a factorial design (experiments 1 to 3 ). Isolates collected from the same cultivar in the same year were also combined to form bulk populations, which were then tested on the two cultivars in a factorial design (experiments 3 to 6). For growth chamber experiments, individual isolates were tested separately from bulk populations due to space limitations. However, the 2005 isolates were tested simultaneously as individual isolates and bulk populations in the same greenhouse experiment (experiment 3).

In growth chamber experiments, precaution against contamination allowed only two blocks per trial when inoculating with individual isolates and four blocks per trial when inoculating with bulk populations (Table 1). Three trials of each of these experiments were conducted each year, for a total of six replications per individual isolate experiment and 12 replications per bulk population experiment. The greenhouse experiment with 2005 isolates

TABLE 1. Description of experiments performed to explore specificity of incomplete resistance to Mycosphaerella graminicola in wheat

\begin{tabular}{|c|c|c|c|c|c|c|c|}
\hline Experiment & Results figure & ANOVA table & Collection year & Evaluation environment ${ }^{\mathrm{a}}$ & Inoculum ${ }^{b}$ & Number of isolates & $\begin{array}{l}\text { Block }(\text { trial })= \\
\text { total replications }\end{array}$ \\
\hline 1 & $1 \mathrm{~A}$ & 2 & 2004 & $\mathrm{GC}$ & Individual & 8 & $2(3)=6$ \\
\hline 2 & 1B & 2 & 2005 & GC & Individual & 8 & $2(3)=6$ \\
\hline 3 & $1 \mathrm{C}, 2 \mathrm{D}$ & 2 & 2005 & $\mathrm{GH}$ & Individual and Bulk & 8 & $2(2)=4$ \\
\hline 4 & $2 \mathrm{~A}$ & 3 & 2004 & $\mathrm{GC}$ & Bulk & 8 & $4(3)=12$ \\
\hline 5 & $2 \mathrm{~B}$ & 3 & 2005 & $\mathrm{GC}$ & Bulk & 8 & $4(3)=12$ \\
\hline 6 & $2 \mathrm{C}$ & 3 & 2004 & $\mathrm{GH}$ & Bulk & 28 & $5(1)=5$ \\
\hline
\end{tabular}

a $\mathrm{GC}=$ growth chamber; $\mathrm{GH}=$ greenhouse.

b Individual = isolates tested individually; Bulk = isolates collected from the same cultivar were combined and tested as bulk populations. 
(experiment 3) consisted of two trials each with two blocks, for a total of four replications. The 2004 experiment using bulk populations in the greenhouse (experiment 6) consisted of one trial with five blocks.

Inoculation. Seeds were planted in 10-cm-square plastic pots and bottom watered in trays as needed. Thirteen seeds were planted per pot and thinned to 10 seedlings per pot prior to inoculation. Sunshine SB40 potting soil (Sun Gro Horticulture Canada Ltd.) was used and amended with $2.5 \mathrm{~g}$ per pot of Osmocote 18-6-12 extended time-release fertilizer (Scott-Sierra Horticultural Products Co., Marysville, $\mathrm{OH}$ ). The growth chamber (Conviron CMP 3023, Controlled Environments Inc., Pembina, ND) was set at $15^{\circ} \mathrm{C}$ and 16-h days with white fluorescent lighting supplemented with incandescent bulbs. The greenhouse was set for $21^{\circ} \mathrm{C}$ days and $18^{\circ} \mathrm{C}$ nights. Daylight was supplemented with high-pressure sodium lights, which were set for 16-h days.

Isolates stored on refrigerated slants were transferred to fresh yeast malt agar slants supplemented with gentamicin 3 days before inoculation and grown at room temperature. On the day of inoculation, conidia were mixed with distilled water and the concentration was adjusted to $10^{6}$ conidia per milliliter using a hemacytometer. A drop of surfactant, Tween 20 (polyoxyethylene sorbitan monolaurate), was added per $50 \mathrm{ml}$ of conidial suspension. In the bulk population suspensions, each isolate was represented in equal frequency. The control "inoculum" was prepared simultaneously and consisted of distilled water and Tween 20.

Inoculations took place when seedlings were 21 days old. Using a hand-held sprayer, four pots of seedlings were sprayed at a time with $25 \mathrm{ml}$ of suspension, which was sufficient to inoculate to runoff. The seedlings were placed on a turntable set at $16 \mathrm{rpm}$ to ensure an equal distribution of conidial suspension. The seedlings were then placed in a randomized complete block design in a mist chamber. The turntable, surrounding area, and workers' hands were cleaned with $95 \%$ ethanol after each conidial suspension in order to prevent cross-contamination. Mist chambers were constructed of a PVC or wooden frame covered with clear plastic sheeting. Ultrasonic humidifiers were attached to a PVC pipe running the length of a chamber with equally spaced holes drilled in the pipe to disperse the mist evenly. The humidifiers were set at medium moisture levels with timed intervals to prevent oversaturation. Seedlings were kept in a mist chamber for $96 \mathrm{~h} \mathrm{im-}$ mediately following inoculation in order to encourage infection. In the growth chamber, the humidifier was then shut off and the plastic cover removed; seedlings remained in the same location. In the greenhouse, seedlings were transferred to a neighboring bench and placed in the same randomized complete block design. All pots were in trays and bottom watered as needed.
Disease assessments. Disease assessments were performed 21 days after inoculation, on the third leaf from the bottom. Leaf length was measured from ligule to blade tip to $1 \mathrm{~mm}$ accuracy, then the average length of necrotic tissue on the leaf blade was measured, disregarding pycnidial density. This measurement included some minor natural tip senescence, as this was sometimes difficult to discern from diseased tissue. Percent necrotic area (disease severity) was used as the response variable in statistical analyses. In previous trials, we have found percent necrosis and percent pycnidial coverage to be very highly correlated, but variation among experimental units often is less for percent necrosis.

Statistical analyses. The six experiments (Table 1) were analyzed separately. For all of the experiments, homogeneity of variance was checked with the Fmax test (22) using the mean square errors of each trial. The results indicated homogeneity of variance among trials of each experiment. In addition, all of the data sets had insignificant $(P>0.10)$ trial by cultivar, trial by isolate source, and trial by isolate interaction effects, thus trials for each experiment were combined. Residual plots for growth chamber studies of individual isolates collected in 2004 and 2005 indicated that log transformation was suitable. The other data sets did not require transformation.

The data were analyzed with the PROC MIXED procedure in SAS version 9.1 (SAS Institute, Cary, NC). Each individual pot was considered an experimental unit, and the seedlings within the pots were considered subsamples. Cultivar, isolate source, isolate (nested within source), and interactions between cultivar and isolate or isolate source were all considered fixed effects. Trial, block (nested within trial), and interactions between these and cultivar, isolate source, or isolate were all considered random effects. Random effects were nonsignificant $(P>0.05)$ in all analyses and thus are not shown in analysis of variance (ANOVA) tables. Significant fixed main effects were not interpreted when they were part of significant interaction terms. Fisher's protected least significant difference $(\mathrm{LSD})(P=0.05)$ test was used to distinguish among means over isolates for the four possible source cultivar $\times$ tester cultivar combinations. The same test was used to determine differences among all possible source cultivar $x$ tester cultivar combinations in the bulk population experiments. Water controls were excluded from the analyses because the amount of disease was low, and including those values would have caused the experiment-wise error to be underestimated. In order to compare treatments to water controls, Dunnett's onetailed $t$ test $(P=0.05)$ was used in a separate analysis of each experiment.

Three different statistical analyses were conducted for the 2005 greenhouse experiment (experiment 3), in which individual isolates and bulk populations were tested simultaneously. First, a

TABLE 2. Analysis of variance for percent disease severity caused by isolates of Mycosphaerella graminicola ${ }^{\mathrm{a}}$

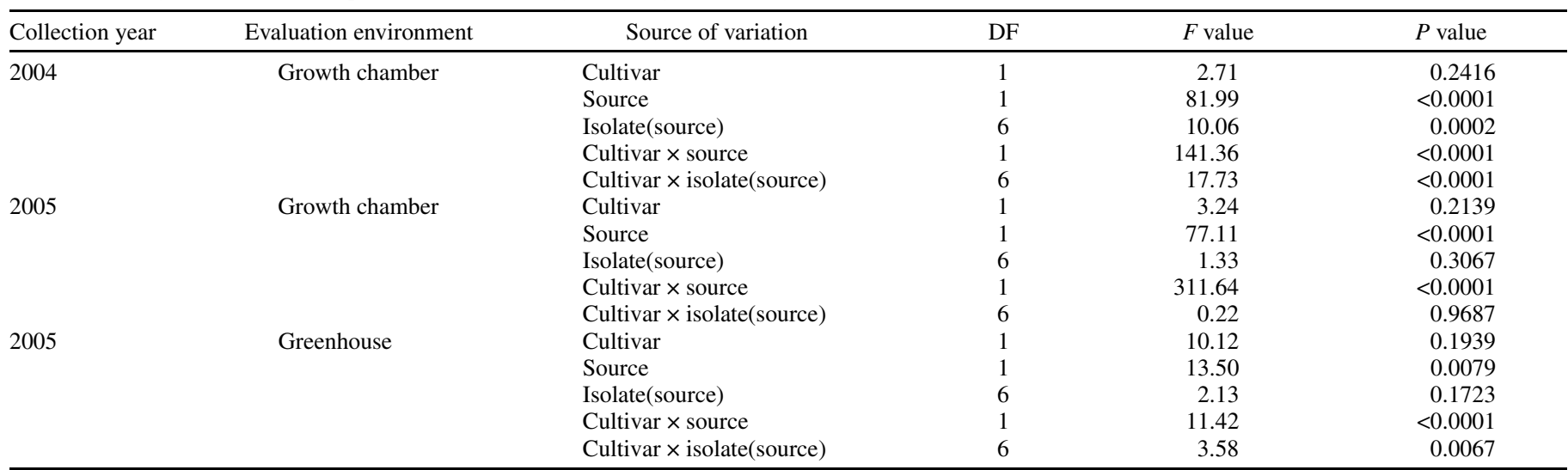

${ }^{a}$ Four isolates were collected from each of the wheat cultivars Foote and Madsen in the field in each of 2 years. Isolates were then inoculated on the same two cultivars grown in a growth chamber or greenhouse. Only fixed effects are shown, as random effects were nonsignificant $(P>0.09)$. Data from growth chamber experiments were log-transformed prior to analysis. 
separate ANOVA was done for the individual isolate data and for the bulk population data so as to provide a direct comparison to ANOVAs of the other experiments. A third analysis combining both individual isolate and bulk data also was conducted, in which each bulk population was considered to be an additional isolate. The means of the individual isolates were then compared to the corresponding bulk populations for each of the four source cultivar $\times$ tester cultivar combinations, using linear contrasts.
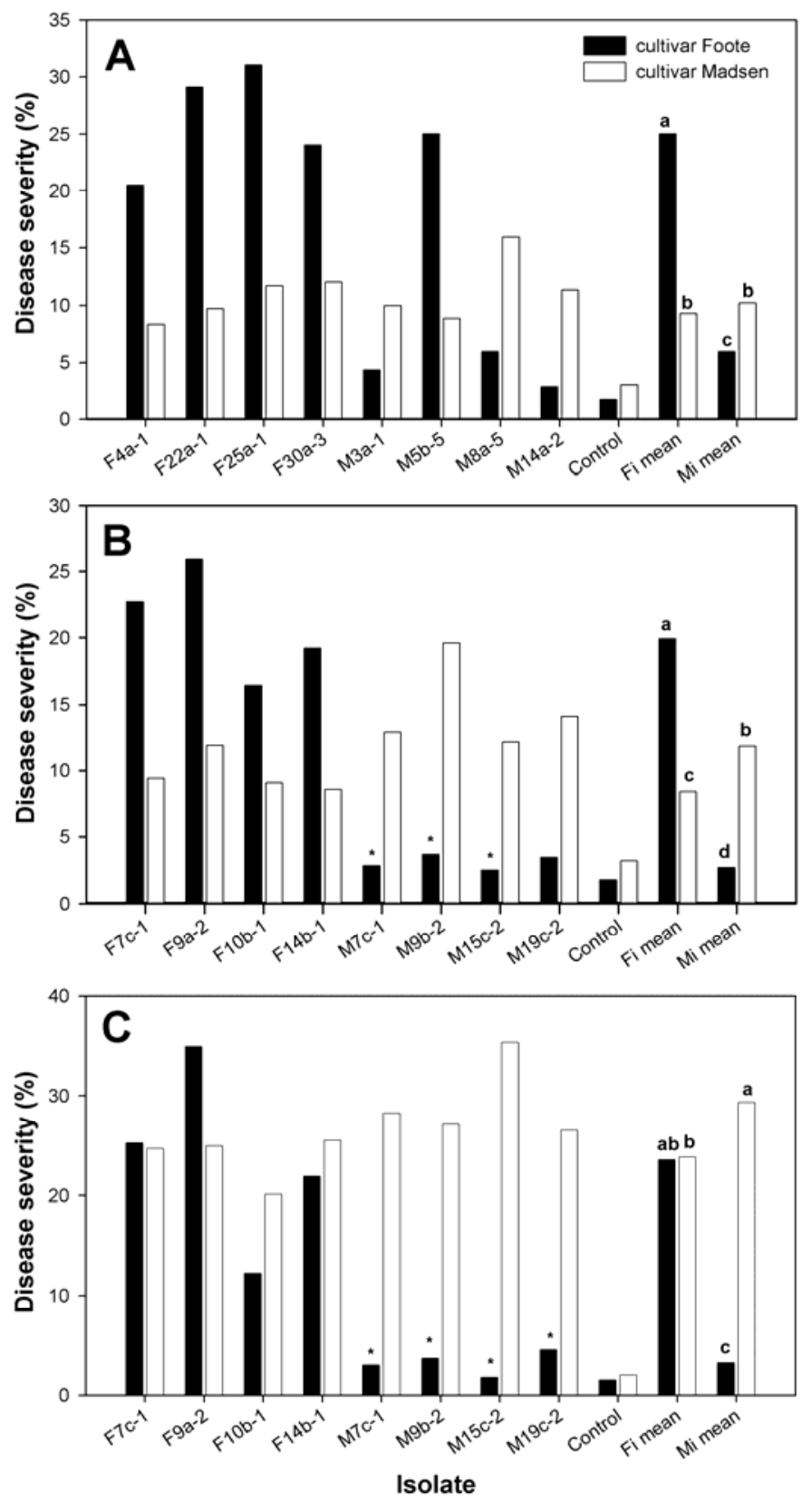

Fig. 1. Disease severity of wheat cultivars Foote and Madsen inoculated with individual isolates of Mycosphaerella graminicola collected from those same two cultivars in the field. A, 2004 isolates evaluated in growth chamber. B, 2005 isolates evaluated in growth chamber. C, 2005 isolates evaluated in greenhouse. Isolates preceded with $\mathrm{F}$ originated on Foote in the field, while isolates preceded with $\mathrm{M}$ originated on Madsen. Fi-mean and Mi-mean indicate means over all four isolates originating from Foote and Madsen, respectively. Bars for isolate means with the same letter are not significantly different $(P \geq 0.05)$ based on Fisher's protected least significant difference. $*$ indicates that disease severity was not significantly different from the water control of the same cultivar based on a one-tailed Dunnett's test $(P \geq 0.05)$. All other treatments were significantly different from the water control of the same cultivar.

\section{RESULTS}

Individual isolates (experiments 1 to 3). Cultivar and isolate source interacted significantly $(P<0.0001)$ in all three experiments (Table 2; Fig. 1). Specificity of isolates to Foote was clearly demonstrated in all experiments, as the mean disease severity caused by isolates collected from Foote and inoculated on Foote was significantly greater than for isolates collected from Madsen. In addition, isolates collected from Madsen caused significantly less disease on Foote than on Madsen in all three experiments. Evidence for specificity of pathogen isolates to Madsen was less clear. In both the growth chamber and greenhouse experiments, all four Madsen isolates collected in 2005 caused higher levels of disease on Madsen than on Foote, though the differences were substantially smaller than for the two source groups inoculated on Foote. Averaged over the 2005 isolates, disease severity on Madsen was significantly higher when inoculated with the Madsen isolates than with the Foote isolates. Specialization of Madsen isolates to the cultivar Madsen was not detected for the 2004 isolates, however. In all experiments, differences in disease severity among isolates were less when inoculated on Madsen than when inoculated on Foote (Fig. 1).

There were some differences in results between the growth chamber and greenhouse experiments. In the growth chamber, Foote isolates caused about twice as much disease on cultivar Foote than cultivar Madsen (Fig. 1A and B), but caused approximately equal amounts of disease on those two cultivars in the greenhouse (Fig. 1C). In addition, ranking for disease severity among the eight isolates collected in 2005 was almost identical in the growth chamber as compared to the greenhouse experiment when inoculated on Foote, but ranking among isolates differed substantially between the two testing environments when inoculated on Madsen (Fig. 1B and C).

Bulk populations (experiments 3 to 6). There were significant interactions $(P \leq 0.01)$ between cultivar and isolate source in all four experiments (Table 3; Fig. 2). As with the individual isolate experiments, there was substantial evidence for pathogen specialization on the cultivar Foote. In all four experiments, populations composed of isolates from the cultivar Foote caused more disease on Foote than did populations composed of isolates collected from Madsen. In addition, isolates collected from Madsen caused significantly less disease on Foote than on Madsen in three of four experiments. The population of isolates collected from Madsen in 2004 caused more disease on Foote than on Madsen in the growth chamber (Fig. 2A), which is in contrast to the mean of these isolates when inoculated individually (Fig. 1A). This likely was caused by the Madsen isolate M5b-5, which has high virulence towards Foote. Adaptation of M. graminicola to Madsen was not demonstrated for the bulk populations, as there was no significant difference in disease severity on Madsen when inoculated with the population from Madsen compared with the population from Foote. As was the case for the individual isolate experiments (Fig. 1), overall disease severity caused by Foote isolates tended to be higher on Foote than on Madsen in the growth chamber experiment (Fig. 2A and B), but not in the greenhouse (Fig. 2C and D).

The 2005 isolates were tested individually and as bulk populations in the same greenhouse experiment. There were no significant differences $(P>0.19)$ between bulk populations (Fig. 1D) and the mean of the same isolates tested individually (mean of individual isolates, Fig. 1C) for any of the four source $\times$ tester combinations.

\section{DISCUSSION}

The nature of resistance of wheat to $M$. graminicola initially was controversial because of difficulties in identifying races of the pathogen that interact differentially with cultivars (16). Sub- 
sequent research established specificity and adaptation of isolates to host cultivars $(3,4,16,17)$. In addition, gene-for-gene relationships have been confirmed with wheat cultivars and pathogen isolates $(7,20)$. In this study, we demonstrated both host-pathogen specificity and pathogen adaptation for incomplete resistance. Observations in the Netherlands suggested a slow erosion of resistance to Septoria tritici blotch on wheat (21) and the resistance of Madsen in the Willamette Valley also eroded gradually (26).

Our study demonstrated clear adaptation of M. graminicola to the cultivar Foote. In all six experiments, pathogen isolates collected from Foote in the field were significantly more virulent on Foote than were isolates collected from the older cultivar Madsen. This result was very robust, as adaptation was found in both growth chamber and greenhouse studies and with both individual isolates and bulk populations. It is not known why, as both single isolates and as bulk populations, Foote isolates caused more disease on Foote than on Madsen in the growth chamber but not in the greenhouse.

Foote showed a qualitative pattern in which isolates expressed either high virulence or low virulence. It thus is possible that resistance to $M$. graminicola in Foote is controlled by a single major gene with incomplete expression, and that adaptation to Foote is simply due to loss of the corresponding avirulence gene. The source of resistance of Foote is unknown, as it was developed from a complex cross with both winter and spring wheat cultivars: Heima//Kalyansona/Bluebird/3/WWP7147, $\mathrm{F}_{1} / 4 / \mathrm{D} 6301 /$ HeinesVII//ERA/3/Buckbuck. Segregation ratios of progeny from a cross between Foote and a known susceptible genotype would be required to elucidate whether a single gene is responsible for the resistance.

Evidence for adaptation of $M$. graminicola to the cultivar Madsen in our study is equivocal. The 2005 isolates collected from Madsen and tested individually caused significantly more disease on Madsen than on Foote in both growth chamber and greenhouse tests, but the 2004 isolates did not. Bulk populations of isolates collected from Madsen did not cause significantly more disease on Madsen than bulks of Foote isolates in any of the four experiments with bulks. Previous studies of both bulk populations (4), and selection coefficients for individual isolates (29) suggested adaptation to Madsen, though the effects were substantially smaller than those obtained for Foote in this study.

Disease on the cultivar Madsen was more consistent across isolates as compared to Foote. This may be, in part, because Madsen has been grown in the Willamette Valley for over a decade, and the pathogen has had significant opportunity to become adapted to that cultivar. Earlier studies $(3,29)$ using isolates collected soon after release of the cultivar Madsen showed continuous variation in virulence among isolates when inoculated on Madsen, how- ever, which is quite different from the qualitative pattern shown in this study for Foote.

Studies of host/pathogen specificity traditionally have used isolates inoculated individually onto different host genotypes. The use of bulk populations, however, allows one to sample a greater diversity of pathogen genotypes and to test them on single experimental units. In addition, bulk populations may represent a more natural situation, as different pathogen genotypes occur in very close proximity in natural epidemics. For example, fine-scale sampling of $M$. graminicola from natural epidemics showed that all isolates collected from different lesions on the same leaf were of a different genotype (23). Further, when individual pycnidia were sampled from within each of five lesions, each lesion was found to contain from two to six genotypes. Interactions such as induced resistance (18) are always potential complications when
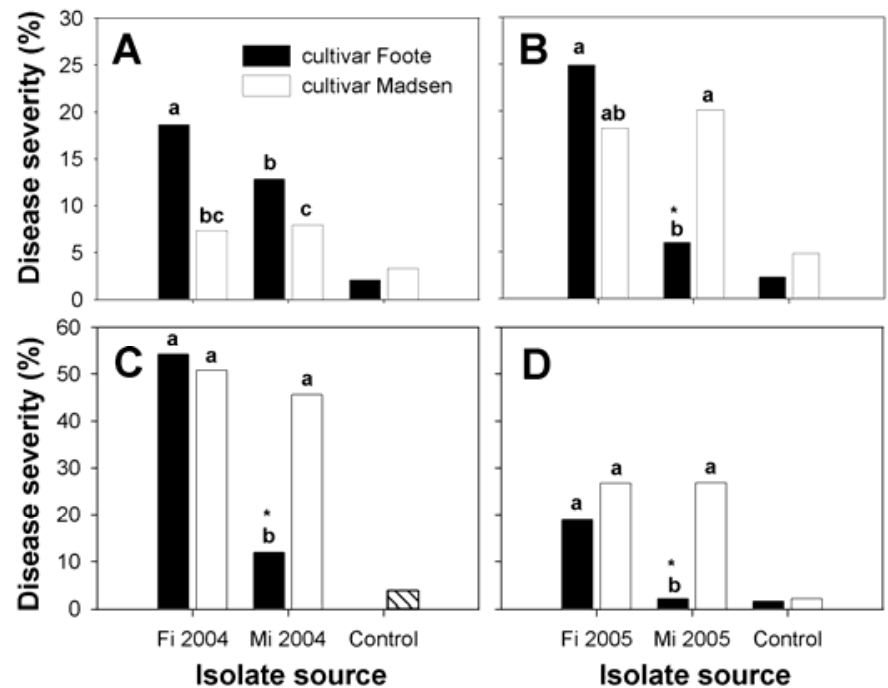

Fig. 2. Disease severity of wheat cultivars Foote and Madsen inoculated with bulk populations of Mycosphaerella graminicola isolates collected from those same two cultivars in the field. A and C, 2004 populations tested in the growth chamber and greenhouse, respectively. B and D, 2005 populations tested in the growth chamber and greenhouse, respectively. Each bulk population was composed of four isolates collected from each of Foote (Fi) or Madsen (Mi), except in $\mathbf{C}$, where there were 14 isolates collected from each cultivar. Black versus white bars indicates bulk populations tested on the cultivar Foote or Madsen, respectively. In $\mathbf{C}$, the water control was the highly susceptible cultivar Stephens; in all other experiments there were controls for each of the cultivars Foote and Madsen. Bars with the same letter are not significantly different $(P \geq 0.05)$ based on Fisher's protected least significant difference. * indicates that disease severity was not significantly different from the water control of the same cultivar (or from the Stephens water control in $\mathbf{C})$ based on a one-tailed Dunnett's test $(P \geq 0.05)$. All other treatments were significantly different from the water control.

TABLE 3. Analysis of variance for percent disease severity caused by bulk populations of Mycosphaerella graminicola

\begin{tabular}{|c|c|c|c|c|c|}
\hline Collection year & Evaluation environment & Source of variation & DF & $F$ value & $P$ value \\
\hline \multirow[t]{3}{*}{2004} & Growth chamber & Cultivar & 1 & 13.42 & 0.0671 \\
\hline & & Source & 1 & 1.47 & 0.3487 \\
\hline & & Cultivar $\times$ source & 1 & 13.51 & 0.0010 \\
\hline \multirow[t]{3}{*}{2004} & Greenhouse & Cultivar & 1 & 10.08 & 0.0080 \\
\hline & & Source & 1 & 25.00 & 0.0003 \\
\hline & & Cultivar $\times$ source & 1 & 15.16 & 0.0021 \\
\hline \multirow[t]{3}{*}{2005} & Growth chamber & Cultivar & 1 & 1.07 & 0.4104 \\
\hline & & Source & 1 & 2.49 & 0.2555 \\
\hline & & Cultivar $\times$ source & 1 & 34.17 & $<0.0001$ \\
\hline \multirow[t]{3}{*}{2005} & Greenhouse & Cultivar & 1 & 32.26 & 0.1110 \\
\hline & & Source & 1 & 9.97 & 0.0134 \\
\hline & & Cultivar $\times$ source & 1 & 10.15 & 0.0129 \\
\hline
\end{tabular}

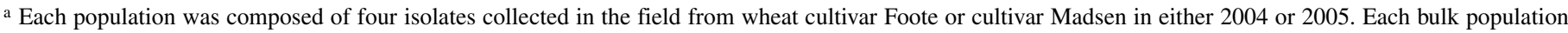
was then inoculated on the same two cultivars grown in a growth chamber or greenhouse. Only fixed effects are shown, as all random effects were nonsignificant $(P>0.06)$. 
using bulk populations. However, we detected no evidence for a strong influence of induced resistance in our experiments, given that bulk populations and the mean of individual isolate tests resulted in similar disease severities. Competition among genotypes is likely to occur in bulk populations, however.

In our study, bulk populations produced levels of disease similar to that of the mean of individual isolates from which the bulk populations were composed and consistently uncovered adaptation of isolates collected from Foote. In the 2004 bulk population experiment in the growth chamber, however, the population from Madsen caused more disease on Foote than on Madsen (Fig. 2), which was generally not the case when isolates were tested individually. Isolate M5b-5, the only Madsen-derived isolate highly virulent on Foote in this study, likely dominated in this population. Further, for the 2005 isolates, adaptation to the cultivar Madsen was detected for the mean of the individual isolates in both the growth chamber and greenhouse, but in neither environment for bulk populations of the same isolates. Thus, interactions among isolates in bulks might mask small fitness differences present among individual isolates.

Reactions of Willamette Valley wheat cultivars to M. graminicola have been monitored for over 15 years. The cultivar Stephens, which dominated the crop area from the 1980s through the mid-1990s, declined in popularity in the mid-1990s almost entirely because of its susceptibility to Septoria tritici blotch (C. C. Mundt, unpublished data). The level of the cultivar's resistance at the time of release is not known, but $M$. graminicola isolates collected from Stephens in the early 1990s showed strong adaptation to Stephens and its sister cultivar, Malcolm (4). The area planted to Madsen increased significantly after a devastating Septoria tritici blotch epidemic in 1993 that affected Stephens severely. Madsen replaced Stephens by the mid/late-1990s and originally showed considerable resistance. The level of resistance in Madsen gradually but substantially eroded (26), though it currently maintains some resistance (C. C. Mundt, unpublished data). Major gene resistance in the cultivar Gene was nearly complete at the time of release in 1993, but broke down catastrophically due to selection of virulent pathogen genotypes $(13,26)$. The current study shows clear adaptation to the cultivar Foote even though resistance appears to be holding up in the field (C. C. Mundt, unpublished data). There clearly will be strong selection during the growing season for pathogen genotypes adapted to a given cultivar. We collected isolates late in the season, when the maximum number of generations of selection would have occurred. However, the high frequency of sexual recombination in $M$. graminicola at the end of the season would reassort genes and make the process of selection for high virulence more gradual (21). Eventually, we would expect alleles for virulence to Foote to reach proportions sufficient to erode resistance. Unfortunately, the durability of the resistance of Foote against Septoria tritici blotch will never be known since the cultivar is being abandoned owing to extreme susceptibility to a new race of $P$. striiformis f. sp. tritici (C. C. Mundt, unpublished data). Regardless, the incomplete resistance of both Madsen and Foote was much more durable than the complete resistance of Gene.

\section{ACKNOWLEDGMENTS}

Helpful suggestions from N. Grunwald and J. Peterson are much appreciated. We also thank L. Wallace for technical assistance.

\section{LITERATURE CITED}

1. Adhikari, T. B., Cavaletto, J. R., Dubcovsky, J., Gieco, J. O., Schlatter, A. R., and Goodwin, S. B. 2004. Molecular mapping of the Stb4 gene for resistance to Septoria tritici blotch in wheat. Phytopathology 94:11981206.

2. Adhikari, T. B., Yang, X., Cavaletto, J. R., Hu, X., Buechley, G., Ohm, H. W., Shaner, G., and Goodwin, S. B. 2004. Molecular mapping of Stb1, a potentially durable gene for resistance to septoria tritici blotch in wheat. Theor. Appl. Genet. 109:944-953.

3. Ahmed, H. U., Mundt, C. C., and Coakley, S. M. 1995. Host-pathogen relationship of geographically diverse isolates of Septoria tritici and wheat cultivars. Plant Pathol. 44:838-847.

4. Ahmed, H. U., Mundt, C. C., Hoffer, M. E., and Coakley, S. M. 1996. Selective influence of wheat cultivars on pathogenicity of Mycosphaerella graminicola (anamorph Septoria tritici). Phytopathology 86:454-458.

5. Arraiano, L. S., Chartrain, L., Bossolini, E., Slatter, H. N., Keller, B., and Brown, J. K. M. 2007. A gene in European wheat cultivars for resistance to an African isolate of Mycosphaerella graminicola. Plant Pathol. 56:7378.

6. Arraiano, L. S., Worland, A. J., Ellerbrook, C., and Brown, J. K. M. 2001. Chromosomal location of a gene for resistance to septoria tritici blotch (Mycosphaerella graminicola) in the hexaploid wheat 'Synthetic 6x'. Theor. Appl. Genet. 103:758-764.

7. Brading, P. A., Verstappen, E. C. P., Kema, G. H. J., and Brown, J. K. M 2002. A gene-for-gene relationship between wheat and Mycosphaerella graminicola, the septoria tritici blotch pathogen. Phytopathology 92:439445.

8. Brown, J. K. M., Kema, G. H. J., Forrer, H.-R., Verstappen, E. C. P., Arraiano, L. S., Brading, P. A., Foster, E. M., Fried, P. M., and Jenny, E. 2001. Resistance of wheat cultivars and breeding lines to septoria tritici blotch caused by isolates of Mycosphaerella graminicola in field trials. Plant Pathol. 50:325-338.

9. Chartrain, L., Berry, S. T., and Brown, J. K. M. 2005. Resistance of wheat line Kavkaz-K4500 L.6.A.4 to Septoria tritici blotch controlled by isolatespecific resistance genes. Phytopathology 95:664-671.

10. Chartrain, L., Brading, P. A., and Brown, J. K. M. 2005. Presence of the Stb6 gene for resistance to septoria tritici blotch (Mycosphaerella graminicola) in cultivars used in wheat-breeding programmes worldwide. Plant Pathol. 54:134-143.

11. Chartrain, L., Brading, P. A., Makepeace, J. C., and Brown, J. K. M. 2004. Sources of resistance to septoria tritici blotch and implications for wheat breeding. Plant Pathol. 53:454-460.

12. Chartrain, L., Joaquim, P., Berry, S. T., Arraiano, L. S., Azanza, F., and Brown, J. K. M. 2005. Genetics of resistance to septoria tritici blotch in the Portuguese wheat breeding line TE 9111. Theor. Appl. Genet. 110:1138-1144.

13. Cowger, C., Hoffer, M. E., and Mundt, C. C. 2000. Specific adaptation by Mycosphaerella graminicola to a resistant wheat cultivar. Plant Pathol. 49:445-451.

14. Cowger, C., McDonald, B. A., and Mundt, C. C. 2002. Frequency of sexual reproduction by Mycosphaerella graminicola on partially resistant wheat cultivars. Phytopathology 92:1175-1181.

15. Cowger, C., and Mundt, C. C. 2002. Aggressiveness of Mycosphaerella graminicola isolates from susceptible and partially resistant wheat cultivars. Phytopathology 92:624-630.

16. Eyal, Z., Amiri, Z., and Wahl, I. 1973. Physiologic specialization of Septoria tritici. Phytopathology 63:1087-1091.

17. Eyal, Z., Scharen, A. L., Huffman, M. D., and Prescott, J. M. 1985 Global insights into virulence frequencies of Mycosphaerella graminicola. Phytopathology 75:1456-1462.

18. Halperin, T., Schuster, S., Pnini-Cohen, S., Zilberstein, A., and Eyal, Z. 1996. The suppression of pycnidial production on wheat seedlings following sequential inoculation by isolates of Septoria tritici. Phytopathology 86:728-732.

19. Kema, G. H. J., Annone, J. G., Sayoud, R., Van Silfhout, C. H. V., Van Ginkel, M., and de Bree, J. 1996. Genetic variation for virulence and resistance in the wheat-Mycosphaerella graminicola pathosystem I. Interactions between pathogen isolates and host cultivars. Phytopathology 86:200-212.

20. Kema, G. H. J., Verstappen, E. C. P., and Waalwijk, C. 2000. Avirulence in the wheat septoria tritici leaf blotch fungus Mycosphaerella graminicola is controlled by a single locus. Mol. Plant-Microbe Interact. 13:1375-1379.

21. Kema, G. H. J., Verstappen, E. C. P., Waalwijk, C., Bonants, P. J. M., de Koning, J. R. A., Hagenaar-de Weerdt, M., Hamza, S., Koeken, J. G. P., and Van der Lee, T. A. J. 1999. Genetics of biological and molecular markers in Mycosphaerella graminicola, the cause of septoria tritici leaf blotch of wheat. Pages 161-180 in Septoria on Cereals: A Study of Pathosystems. J. A. Lucas, P. Bowyer, and H. M Anderson, eds. CAB International, Wallingford, UK.

22. Kuehl, R. O. 2000. Page 666 in: Design of Experiments: Statistical Principles of Research Design and Analysis. Brooks/Cole, Pacific Grove, CA.

23. Linde, C. C., Zhan, J., and McDonald, B. A. 2002. Population structure of Mycosphaerella graminicola: From lesions to continents. Phytopathology 92:946-955

24. McCartney, C. A., Brule-Babel, A. L., and Lamari, L. 2002. Inheritance of 
race-specific resistance to Mycosphaerella graminicola in wheat. Phytopathology 92:138-144.

25. McDonald, B. A., Mundt, C. C., and Chen, R.-S. 1996. The role of selection on the genetic structure of pathogen populations: Evidence from field experiments with Mycosphaerella graminicola on wheat. Euphytica 92:73-80.

26. Mundt, C. C., Cowger, C., and Garrett, K. A. 2002. Relevance of integrated disease management to resistance durability. Euphytica 124:245-252.

27. Mundt, C. C., Hoffer, M. E., Ahmed, H. U., Coakley, S. M., DiLeone, J.
A., and Cowger, C. 1999. Population genetics and host resistance. Pages 115-130 in: Septoria on Cereals: A Study of Pathosystems. J. A. Lucas, P. Bowyer, and H. M. Anderson, eds. CAB International, Wallingford, UK.

28. Zhan, J., Linde, C. C., Jurgens, T., Merz, U., Steinebrunner, F., and McDonald, B. A. 2005. Variation for neutral markers is correlated with variation for quantitative traits in the plant pathogenic fungus Mycosphaerella graminicola. Mol. Ecol. 14:2683-2693.

29. Zhan, J., Mundt, C. C., Hoffer, M. E., and McDonald, B. A. 2002. Local adaptation and effect of host genotype on the rate of pathogen evolution: An experimental test in a plant pathosystem. J. Evol. Biol. 15:634-647. 